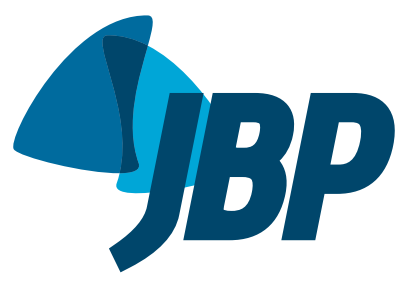

\title{
Association between physical activity in daily life and pulmonary function in adult smokers
}

\author{
Miriane Lilian Barboza', Alan Carlos Brisola Barbosa', \\ Giovanna Domingues Spina', Evandro Fornias Sperandio', Rodolfo Leite Arantes², \\ Antonio Ricardo de Toledo Gagliardi², Marcello Romiti², Victor Zuniga Dourado
}

1. Departamento de Ciências do Movimento Humano, Laboratório de Epidemiologia e Movimento Humano EPIMOV - Universidade Federal de São Paulo, Santos (SP) Brasil.

2. Instituto de Medicina Cardiovascular Angiocorpore, Santos (SP) Brasil.

Submitted: 15 June 2015. Accepted: 30 November 2015

Study carried out in the Departamento de Ciências do Movimento Humano, Laboratório de Epidemiologia e Movimento Humano - EPIMOV Universidade Federal de São Paulo Santos (SP) Brasil.

\begin{abstract}
Objective: To determine whether the level of physical activity in daily life (PADL) is associated with pulmonary function in adult smokers. Methods: We selected 62 adult smokers from among the participants of an epidemiological study conducted in the city of Santos, Brazil. The subjects underwent forced spirometry for pulmonary function assessment. The level of PADL was assessed by the International Physical Activity Questionnaire and triaxial accelerometry, the device being used for seven days. The minimum level of PADL, in terms of quantity and intensity, was defined as 150 min/week of moderate to vigorous physical activity. Correlations between the studied variables were tested with Pearson's or Spearman's correlation coefficient, depending on the distribution of the variables. We used linear multiple regression in order to analyze the influence of PADL on the spirometric variables. The level of significance was set at $5 \%$. Results: Evaluating all predictors, corrected for confounding factors, and using pulmonary function data as outcome variables, we found no significant associations between physical inactivity, as determined by accelerometry, and spirometric indices. The values for FVC were lower among the participants with arterial hypertension, and $\mathrm{FEV}_{1} / \mathrm{FVC}$ ratios were lower among those with diabetes mellitus. Obese participants and those with dyslipidemia presented with lower values for $F V C$ and $F E V_{1}$. Conclusions: Our results suggest that there is no consistent association between physical inactivity and pulmonary function in adult smokers. Smoking history should be given special attention in COPD prevention strategies, as should cardiovascular and metabolic comorbidities.
\end{abstract}

Keywords: Smoking; Respiratory function tests; Motor activity; Accelerometry.

\section{INTRODUCTION}

Smoking is a major public health problem worldwide. In the 20th century, tobacco use killed 100 million people worldwide. Smoking accounts for 5.4 million deaths per year worldwide, and it is estimated that it will account for more than 8.0 million deaths per year in 2030 . Approximately $80 \%$ of these deaths will occur in developing countries, and smoking is currently the leading cause of preventable death worldwide. ${ }^{(1)}$

The impact of tobacco use on health is well known, tobacco use accounting for $90 \%$ of all cases of lung cancer, $75 \%$ of all cases of chronic bronchitis, and $25 \%$ of all cases of ischemic heart disease. ${ }^{(2)}$ Individuals who smoke more than 20 cigarettes per day are significantly different from nonsmokers in terms of their $\mathrm{FEV}_{1}{ }^{(3)}$ This is due to the fact that smoking causes acute lung changes, including changes in airflow resistance, cough, and airway irritation. ${ }^{(4)}$

Lung function decline is less pronounced in smokers who engage in moderate- to high-intensity physical activity. ${ }^{(5)}$ Studies have shown that regular physical activity is effective in preventing chronic diseases such as cardiovascular disease, diabetes, cancer, hypertension, obesity, depression, and osteoporosis. It has been suggested that there is a significant association between physical activity and health status, increased physical fitness resulting in additional health benefits. ${ }^{(6)}$ Other studies have shown that endurance training in nonsmokers results in adaptations of the cardiorespiratory and neuromuscular systems that increase the supply of oxygen to the mitochondria, thus contributing to maintaining physical fitness. ${ }^{(7,8)}$ It has been suggested that smoking reduces cardiorespiratory fitness and lung function. ${ }^{(9,10)}$ In addition, significant differences have been found between physically active and physically inactive smokers regarding fatigue immediately after the six-minute walk test and during the recovery period, at two minutes after the test. ${ }^{(11)}$

Regular physical exercise can counter the negative effects of smoking through an anti-inflammatory and antioxidant mechanism. Physical activity and smoking

\section{Correspondence to:}

Victor Zuniga Dourado. Laboratório de Epidemiologia e Movimento Humano, Universidade Federal de São Paulo, Rua Silva Jardim, 136, sala 338, Vila Mathias, CEP 11015020, Santos, SP, Brasil.

Tel.: 5513 3878-3803. E-mail: vzdourado@yahoo.com.br

Financial support: This study received financial support from the Fundação de Amparo à Pesquisa do Estado de São Paulo (FAPESP, São Paulo Research Foundation; Grant 2011/07282-6). Miriane Lilian Barboza and Alan Carlos Brisola Barbosa receive financial support from the Programa Institucional de Bolsas de Iniciação Cientifica of the Brazilian Conselho Nacional de Desenvolvimento Cientifico e Tecnológico (CNPq, National Council for Scientific and Technological Development). 
interact antagonistically: inflammatory markers that are produced in the lung and are related to a decline in cardiorespiratory fitness are suppressed by physical exercise. ${ }^{(5)}$

Physical activity can be assessed by a variety of methods, including direct observation, questionnaires, self-report diaries, and motion sensors, such as pedometers and accelerometers. ${ }^{(12)}$ Objective assessment is performed by motion sensors, which are instruments that are used in order to detect body motion and determine the level of physical activity in daily life (PADL) over a period of time. Accelerometers are real-time motion capture sensors that are sensitive to acceleration. ${ }^{(13)}$

Few studies have examined the preventive effect of physical activity on the lung function of smokers, the level of PADL having been determined on the basis of self-reports, face-to-face interviews, or physical activity questionnaires. Using pedometers, Furlanetto et al. (11) found that the mean number of daily steps was significantly lower in adult smokers than in adult controls, the former also having lower physical capacity, worse lung function, and greater sensation of fatigue. However, there is a lack of studies in which the level of PADL in smokers is more accurately determined with the use of triaxial accelerometers.

There is evidence that a higher level of PADL reduces smoking-related complications. However, there is a need for further clarification of the association between the level of PADL and lung function in smokers. If this association is found to be consistent, preventive strategies can be devised. Longitudinal studies of the role that a higher level of objectively measured PADL has in preventing lung function decline in smokers could contribute to preventing smoking-related complications, which consume a significant proportion of health care resources in Brazil and the world. ${ }^{(14)}$

We hypothesized that smokers who have a higher level of PADL (more accurately determined by triaxial accelerometry) have relatively preserved lung function, regardless of their smoking history. Confirmation of our hypothesis would support the need for strategies to increase the level of PADL in smokers in order to reduce the damage caused by smoking. Therefore, we sought to determine whether the level of PADL, as determined by triaxial accelerometry, was associated with lung function in adult smokers.

\section{METHODS}

This was a cross-sectional study involving a convenience sample of adult smokers selected from among the participants of a study conducted in the Federal University of São Paulo Laboratory of Epidemiology and Human Movement, located in the city of Santos, Brazil. The study included 62 adult smokers who were 20 years of age or older and had no cardiac, respiratory, or metabolic diseases limiting their exercise capacity. In brief, this was a population-based epidemiological study whose primary objective was to determine the association of sedentary behavior and physical inactivity with the development of chronic diseases. The exclusion criteria were as follows: a spirometric diagnosis of COPD; problems indicating inability to perform PADL adequately; being a smoker with a smoking history of fewer than 1.5 pack-years or more than 50 pack-years; and being a former smoker. ${ }^{(15)}$

The following demographic variables were analyzed: age; gender; race; place of birth; level of education; and socioeconomic status. After being selected for inclusion, all participants were informed of the procedures, discomfort, and risks associated with the present study and gave written informed consent. The study project was approved by the Federal University of São Paulo Human Research Ethics Committee (Protocol no. 186.796).

Initial clinical evaluation included history taking for previous health problems and use of medications. The risk of cardiovascular events was determined on the basis of the following risk factors: age; family history; smoking history; hypertension; dyslipidemia or hypercholesterolemia; diabetes or hyperglycemia; obesity; and sedentary lifestyle.

Smoking status was determined by self-report, and smoking history was calculated by multiplying the duration of smoking in years by the number of cigarettes smoked per day and dividing the result by 20 (the number of cigarettes in one pack). Individuals who reported current smoking and having smoked 100 or more cigarettes in their lifetime at the time of the study were defined as smokers. ${ }^{(15)}$

After anthropometric measurements, including weight, height, and BMI calculation, all participants were evaluated as described below.

Lung function was assessed by forced spirometry (Quark PFT; Cosmed, Rome, Italy). FEV ${ }_{1}$, FVC, FEV $_{1} /$ FVC, and PEF were determined in accordance with the American Thoracic Society criteria. ${ }^{(16)}$ Spirometric indices were expressed as absolute values and as a percentage of reference values. ${ }^{(17)}$

The level of PADL was determined by the International Physical Activity Questionnaire (IPAQ), which assesses total energy expenditure in metabolic equivalent task-minutes per week (MET-min/wk) and time spent in daily physical activity. PADL was classified as vigorous, moderate, or light, measured in MET-min/wk, and divided into four domains: work; transport; household chores; and recreation and leisure. The total IPAQ score is calculated by summing the individual domain scores. The IPAQ-long form was used, consisting of 27 questions regarding physical activity. The participants were instructed to answer the questions on the basis of the week prior to the administration of the IPAQ. ${ }^{(18)}$ The level of PADL was also assessed with a widely used triaxial accelerometer (GT3X ActiGraph; MTI, Pensacola, FL, USA). ${ }^{(19-22)}$ A triaxial accelerometer measures the duration and intensity of physical activity. The participants were instructed to wear the device on an elastic belt placed on their dominant hip and left 
in place for seven days. A valid day was defined as at least $12 \mathrm{~h}$ of accelerometer use. All participants were instructed to remove the device before engaging in water-based activities, such as bathing and swimming, and at bedtime. Only the data from the participants who used the accelerometer for at least four valid days were analyzed. (19) On the basis of its intensity, physical activity was classified as follows: physical inactivity or light physical activity, fewer than 3.00 MET-min/wk; moderate physical activity, 3.00-5.99 MET-min/wk; hard physical activity, 6.00-8.99 MET-min/wk; and very hard physical activity, $\geq 9.00 \mathrm{MET}-\mathrm{min} / \mathrm{wk}^{(23)}$ The minimum level of PADL, in terms of quantity and intensity, was defined as $150 \mathrm{~min} /$ week of moderate to vigorous physical activity. ${ }^{(24)}$ The participants who were unable to achieve that level of PADL were considered to be physically inactive.

In the present study, statistical analysis was performed with the IBM SPSS Statistics software package, version 23 (IBM Corporation, Armonk, NY, USA). The Kolmogorov-Smirnov test was used in order to determine the normality of continuous variables. Data are presented as mean \pm standard deviation or as median (interquartile range).

The study sample size was calculated on the basis of the number of independent variables of interest for inclusion in the multiple regression model. Outcome variables in the regression models included percent predicted $\mathrm{FEV}_{1}$ and FVC. The models were adjusted for age, gender, weight, height, and six other variables. Smoking history was considered to be the main predictor. Possible predictors were initially evaluated in categories. Demographic and anthropometric characteristics were taken into consideration, as were cardiovascular risk factors. After the bivariate analysis, the variables that were found to be significantly associated with the spirometric indices were included in the multiple regression model, as follows: age; gender; presence of hypertension; presence of diabetes mellitus; IPAQ household chores domain score; daily energy expenditure in kcal; and physical inactivity.

The Student's t-test or the Mann-Whitney test was used in order to compare the spirometric indices between males and females according to the presence of comorbidities, such as hypertension, diabetes mellitus, dyslipidemia, obesity, and physical inactivity.

Correlations between the studied variables were tested with Pearson's or Spearman's correlation coefficient, depending on the distribution of the variables. The level of significance was set at $5 \%$.

\section{RESULTS}

Among the 62 volunteers in the study sample, obese individuals and females predominated (Table 1). There were significant differences between males and females regarding smoking history, weight, and BMI.

Table 2 shows the correlations between PADL and lung function, FVC having been found to correlate significantly with the IPAQ household chores domain score, energy expenditure in $\mathrm{kcal} / \mathrm{day}$, and hard physical activity in $\mathrm{h}$ $(p<0.05$ for all). The aforementioned variables were also found to correlate significantly with $\mathrm{FEV}_{1}$. The household chores domain scores were the only IPAQ domain scores that correlated significantly with lung function. PEF was found to correlate significantly with the IPAQ household chores domain score, light physical activity, and hard physical activity. Table 3 shows the bivariate association between lung function data and cardiovascular risk factors. FVC was found to be reduced in the participants with arterial hypertension, and the $\mathrm{FEV}_{1} / \mathrm{FVC}$ ratio was found to be reduced in those with diabetes mellitus. Obese participants and those with dyslipidemia were found to have reduced FVC and $\mathrm{FEV}_{1}$. No significant associations were found between physical inactivity, as determined by accelerometry, and spirometric indices.

Evaluating all predictors, corrected for confounding factors, and using lung function data (FVC and FEV ${ }_{1}$, both in $\%$ of predicted) as outcome variables, we found that the variables that remained in the model as predictors of lung function were smoking history and the presence of diabetes, as predictors of FVC, and smoking history and the presence of arterial hypertension, as predictors of FEV $_{1}$ (Table 4).

\section{DISCUSSION}

The present study investigated the association between the level of PADL and lung function in adult smokers without respiratory disease. The level of PADL was directly assessed by triaxial accelerometry over the course of seven days. To our knowledge, there is little information regarding the use of triaxial accelerometry for determining the level of PADL. After adjustment for the main confounding factors, no association was found between an adequate level of PADL and better lung function.

As expected, smoking history was a predictor of worse FVC and $\mathrm{FEV}_{1}$, even after having been adjusted for confounding factors. Studies have shown that smoking history is the main predictor of reduced $\mathrm{FEV}_{1}$ in smokers with a normal $\mathrm{FEV}_{1} / \mathrm{FVC}$ ratio. ${ }^{(25)}$ Smoking is also associated with dysregulation of gene expression in the small airway epithelium and accelerates the aging of the airways, as well as being the principal factor responsible for progressive lung function decline. (26)

Lallukka et al. ${ }^{(27)}$ conducted a cohort study and concluded that smoking and physical inactivity are associated with disability retirement and that even hard physical activity is not sufficient to eliminate the adverse effects that smoking has on health. Elderly smokers have reduced exercise capacity when compared with elderly never-smokers, and tobacco exposure is associated with reduced quality of life regardless of the level of physical activity. ${ }^{(28)}$ Smoking is associated with evidence of mild obstruction and accelerates lung function decline in adolescents. Female adolescents are possibly more vulnerable to the effects of smoking on lung function than are male adolescents. ${ }^{(29)}$ We believe 
Table 1. General characteristics of the sample $(N=62) .^{a}$

\begin{tabular}{lcc}
\multicolumn{1}{c}{ Variable } & Males & Females \\
$(\mathbf{n}=\mathbf{2 0})$ & $(\mathbf{n}=\mathbf{4 2})$ \\
Age, years & $47 \pm 14$ & $53 \pm 8$ \\
Smoking history, pack-years & $12.7(3.2-20.0)^{*}$ & $22.5(11.7-40.0)$ \\
Weight, kg & $80.2 \pm 12.3^{*}$ & $74.6 \pm 19.9$ \\
Height, $\mathrm{cm}$ & $1.71 \pm 0.07^{*}$ & $1.57 \pm 0.07$ \\
BMI, kg/m² & $27.4 \pm 4.5^{*}$ & $29.8 \pm 7.07$ \\
Risk factors, $\mathrm{n}(\%)$ & & \\
$\quad$ Hypertension & $4(20)$ & $13(31)$ \\
$\quad$ Obesity & $5(25)$ & $20(47)$ \\
Diabetes & $2(10)$ & $10(23)$ \\
Dyslipidemia & $5(25)$ & $18(42)$ \\
Physical inactivity & $7(35)$ & $14(33)$ \\
\hline
\end{tabular}

${ }^{a}$ Data presented as mean \pm SD or median (interquartile range), except where otherwise indicated. ${ }^{*} p<0.05$.

Table 2. Statistical correlations between lung function and physical activity in daily life.

\begin{tabular}{lccccccc}
\multicolumn{1}{c}{ Lung function } & \multicolumn{7}{c}{ Physical activity in daily life } \\
& IPAQ-HC $^{\text {a }}$ & EE, kcal/day & WST, $\mathbf{h}$ & WLPA, $\mathbf{h}$ & WMPA, $\mathbf{h}$ & WVPA, $\mathbf{h}$ & WVVPA, $\mathbf{h}$ \\
FVC, L & $0.432^{*}$ & $0.320^{*}$ & 0.182 & 0.203 & 0.104 & $0.375^{*}$ & 0.034 \\
$\mathrm{FEV}_{1}$, L & $0.400^{*}$ & $0.330^{*}$ & 0.218 & 0.186 & 0.103 & $0.346^{*}$ & 0.036 \\
$\mathrm{FEV}_{1}$ /FVC & 0.110 & 0.064 & 0.205 & 0.064 & 0.023 & 0.071 & 0.018 \\
$\mathrm{FEV}_{1}$ /FVC, \% predicted & 0.057 & 0.046 & 0.241 & 0.059 & 0.012 & 0.084 & 0.001 \\
PEF, L/min & $0.451^{*}$ & 0.191 & 0.246 & $0.264^{*}$ & 0.052 & $0.392^{*}$ & 0.008 \\
\hline
\end{tabular}

IPAQ-HC: International Physical Activity Questionnaire household chores domain score; EE: energy expenditure; WST: weekly sedentary time; WLPA: weekly light physical activity; WMPA: weekly moderate physical activity; WVPA: weekly vigorous physical activity; and WVVPA: weekly very vigorous physical activity. ${ }^{a}$ Energy expenditure measured in metabolic equivalent task-minutes per week. ${ }^{*} \mathrm{p}<0.05$.

Table 3. Relationship between lung function data and cardiovascular risk factors.

\begin{tabular}{|c|c|c|c|c|c|c|}
\hline \multirow[t]{2}{*}{ Risk factors } & & \multicolumn{5}{|c|}{ Lung function data } \\
\hline & & FVC, L & $\begin{array}{l}\text { FVC, \% } \\
\text { predicted }\end{array}$ & $\mathrm{FEV}_{1}, \mathrm{~L}$ & $\begin{array}{l}\mathrm{FEV}_{1}, \% \\
\text { predicted }\end{array}$ & $\begin{array}{c}\mathrm{FEV}_{1} / \mathrm{FVC}, \% \\
\text { predicted }\end{array}$ \\
\hline \multirow[t]{2}{*}{ Arterial hypertension } & Yes & $2.81 \pm 0.62^{*}$ & $86 \pm 14$ & $2.22 \pm 0.53$ & $84 \pm 16$ & $78 \pm 6$ \\
\hline & No & $3.72 \pm 0.10^{*}$ & $94 \pm 12$ & $2.88 \pm 0.89$ & $95 \pm 12$ & $82 \pm 5$ \\
\hline \multirow[t]{2}{*}{ Diabetes mellitus } & Yes & $2.74 \pm 0.85$ & $83 \pm 10$ & $2.29 \pm 0.69$ & $86 \pm 10$ & $84 \pm 2^{*}$ \\
\hline & No & $3.47 \pm 1.03$ & $94 \pm 12$ & $2.80 \pm 0.87$ & $94 \pm 15$ & $80 \pm 6^{*}$ \\
\hline \multirow[t]{2}{*}{ Dyslipidemia } & Yes & $2.98 \pm 0.67^{*}$ & $92 \pm 12$ & $2.44 \pm 0.52^{*}$ & $93 \pm 13$ & $82 \pm 5$ \\
\hline & No & $3.53 \pm 1.16^{*}$ & $92 \pm 13$ & $2.85 \pm 0.98^{*}$ & $92 \pm 15$ & $80 \pm 6$ \\
\hline \multirow[t]{2}{*}{ Obesity } & Yes & $2.94 \pm 0.59^{*}$ & $88 \pm 11$ & $2.41 \pm 0.52^{*}$ & $89 \pm 14$ & $81 \pm 6$ \\
\hline & No & $3.58 \pm 1.19^{*}$ & $95 \pm 13$ & $2.90 \pm 0.99^{*}$ & $94 \pm 14$ & $80 \pm 5$ \\
\hline \multirow[t]{2}{*}{ Physical inactivity } & Yes & $3.27 \pm 1.11$ & $92 \pm 15$ & $2.62 \pm 0.97$ & $91 \pm 18$ & $79 \pm 6$ \\
\hline & No & $3.35 \pm 1.00$ & $92 \pm 12$ & $2.74 \pm 0.81$ & $93 \pm 12$ & $82 \pm 5$ \\
\hline
\end{tabular}

$* p<0.05$.

Table 4. Multivariate regression results with the main predictors of lung function. ${ }^{\mathrm{a}}$

\begin{tabular}{ccccccc} 
Outcome & Predictors & Coefficient & Standard error & $\mathbf{p}$ & $\mathbf{\Delta R}$ & $\mathbf{R}^{\mathbf{2}}$ \\
FVC, \% predicted & Smoking history & -0.218 & 0.065 & 0.001 & 0.110 & 0.246 \\
& Diabetes mellitus & -12.266 & 3.763 & 0.002 & 0.136 & \\
FEV $_{1}, \%$ predicted & Smoking history & -0.202 & 0.074 & 0.009 & 0.135 & 0.225 \\
& Arterial hypertension & -9.883 & 3.781 & 0.011 & 0.090 & \\
\hline
\end{tabular}

aModel adjusted for age, gender, weight, height, hypertension, diabetes, physical inactivity (determined by triaxial accelerometry), and International Physical Activity Questionnaire score.

that the benefits of PADL were not enough to make up for the damage caused by smoking.

We observed a crucial association between the presence of diabetes mellitus and lung function in our participants. Our results are in agreement with those of previous studies. ${ }^{(30,31)}$ Lung volume changes reducing lung compliance and DLCO have been described in patients with diabetes. This is probably due to a reduction in pulmonary capillary blood volume as a result of diabetes mellitus. Impaired lung function in 
individuals with diabetes suggests that the lung is a "target organ" in diabetes mellitus. ${ }^{(32)}$ Systematic reviews have examined lung function in patients with diabetes mellitus. Reduced $\mathrm{FEV}_{1}$ and FVC have been found to be associated with type 1 diabetes and type 2 diabetes. ${ }^{(33)}$ Our results suggest that this association remains significant even in smokers with varying history of smoking. Therefore, diabetes mellitus should be considered a major risk factor for lung function decline and, eventually, COPD. According to the aforementioned studies, moderate to high levels of regular physical activity are associated with reduced lung function decline and reduced risk of COPD in smokers. ${ }^{(5,34)}$ This difference can be attributed to the methods used in order to determine the level of PADL. In the present study, we used triaxial accelerometry, which precisely measures the amount and intensity of PADL. The aforementioned studies involved the use of questionnaires. Despite the size of those studies, the major limitation of questionnaires is that they overestimate the level of PADL. Triaxial motion sensors can overcome some of the limitations of self-report instruments, are not affected by random and systematic errors introduced by interviewees and interviewers, and provide valid and reliable estimates of basic features such as the frequency, duration, and intensity of physical activity, as well as the pattern of physical activity. ${ }^{(35)}$ An accurate assessment of physical activity is extremely important when the relationship between exposure to physical activity and a range of health outcomes (e.g., cardiovascular disease, hypertension, and obesity) is examined. ${ }^{(36)}$ In addition, self-reported physical activity is highly susceptible to inaccuracy because self-report instruments depend on the ability of individuals to recall and report their physical activity. ${ }^{(23)}$ Our results suggest the need for longitudinal epidemiological studies to investigate the association between lung function and PADL, the latter being more accurately assessed by motion sensors.

The major limitation of the present study is its convenience sample, which can explain the predominance of females and the difference in smoking history between males and females. However, the sample size was sufficient to adjust the regression models to the main confounders of clinical interest.

Our results suggest that there is no association between physical inactivity and lung function in adult smokers, as well as reinforcing the importance of smoking cessation and preventing comorbidities such as diabetes mellitus and arterial hypertension in order to prevent lung function decline and COPD. Therefore, health professionals should focus on health promotion instructions and strategies, as well as on preventing comorbidities in smokers and the general population.

\section{ACKNOWLEDGMENTS}

The authors would like to thank the Angiocorpore Institute of Cardiovascular Medicine for their support.

\section{REFERENCES}

1. World Health Organization. WHO Report on the Global Tobacco Epidemic 2008: The Mpower Package. Geneva: World Health Organization; 2008.

2. Wünsch Filho V, Mirra AP, López RV, Antunes LF. Tobacco smoking and cancer in Brazil: evidence and prospects [Article in Portuguese]. Rev Bras Epidemiol. 2010;13(2):175-87. http://dx.doi.org/10.1590/ S1415-790X2010000200001

3. Urrutia I, Capelastegui A, Quintana JM, Mu-iozguren N, Basagana $X$, Sunyer J, et al. Smoking habit, respiratory symptoms and lung function in young adults. Eur J Public Health. 2005;15(2):160-5. http:// dx.doi.org/10.1093/eurpub/cki113

4. Tantisuwat A, Thaveeratitham P. Effects of smoking on chest expansion, lung function, and respiratory muscle strength of youths. J Phys Ther Sci. 2014;26(2):167-70. http://dx.doi.org/10.1589/ jpts.26.167

5. Garcia-Aymerich J, Lange P, Benet M, Schnohr P, Antó JM. Regular physical activity modifies smoking-related lung function decline and reduces risk of chronic obstructive pulmonary disease: a populationbased cohort study. Am J Respir Crit Care Med. 2007;175(5):458-63. http://dx.doi.org/10.1164/rccm.200607-8960C

6. Warburton DE, Nicol CW, Bredin SS. Health benefits of physical activity: the evidence. CMAJ. 2006;174(6):801-9. http://dx.doi. org/10.1503/cmaj.051351

7. Cheng YJ, Macera CA, Addy CL, Sy FS, Wieland D, Blair SN. Effects of physical activity on exercise tests and respiratory function. $\mathrm{Br} J$ Sports Med. 2003;37(6):521-8. http://dx.doi.org/10.1136/ bjsm.37.6.521

8. Jones AM, Carter $\mathrm{H}$. The effect of endurance training on parameters of aerobic fitness. Sports Med. 2000;29(6):373-86. http://dx.doi. org/10.2165/00007256-200029060-00001

9. Hashizume K, Kusaka Y, Kawahara K. Effects of cigarette smoking on endurance performance levels of 16- to 19-year-old males. Environ Health Prev Med. 1999;4(2):75-80. http://dx.doi.org/10.1007/ BF02931998

10. Lee $C L$, Chang WD. The effects of cigarette smoking on aerobic and

anaerobic capacity and heart rate variability among female university students. Int J Womens Health. 2013;5:667-79. http://dx.doi. org/10.2147/IJWH.S49220

11. Furlanetto KC, Mantoani LC, Bisca G, Morita AA, Zabatiero J, Proença $M$, et al. Reduction of physical activity in daily life and its determinants in smokers without airflow obstruction. Respirology. 2014;19(3):369-75. http://dx.doi.org/10.1111/resp.12236

12. Atkin AJ, Gorely T, Clemes SA, Yates T, Edwardson C, Brage S, et al. Methods of measurement in epidemiology: sedentary behaviour. Int J Epidemiol. 2012;41(5):1460-71. http://dx.doi.org/10.1093/ije/ dys 118

13. Pitta F, Troosters T, Probst VS, Spruit MA, Decramer M, Gosselink R. Quantifying physical activity in daily life with questionnaires and motion sensors in COPD. Eur Respir J. 2006;27(5):1040-55. http:// dx.doi.org/10.1183/09031936.06.00064105

14. Pinto M, Ugá MA. Os custos de doenças tabaco-relacionadas para o Sistema Único de Saúde. Cad Saude Publica. 2010;26(6):1234-45. http://dx.doi.org/10.1590/S0102-311X2010000600016

15. Santos JD, Silveira DV, Oliveira DF, Caiaffa WT. Instruments used to evaluate smoking habits: a systematic review [Article in Portuguese]. Cien Saude Colet. 2011;16(12):4707-20. http://dx.doi.org/10.1590/ S1413-81232011001300020

16. Miller MR, Hankinson J, Brusasco V, Burgos F, Casaburi R, Coates A et al. Standardisation of spirometry. Eur Respir J. 2005;26(2):319-38. http://dx.doi.org/10.1183/09031936.05.00034805

17. Pereira CA, Sato T, Rodrigues SC. New reference values for forced spirometry in white adults in Brazil. J Bras Pneumol. 2007;33(4):397406. http://dx.doi.org/10.1590/S1806-37132007000400008

18. Hallal PC, Gomez LF, Parra DC, Lobelo F, Mosquera J, Florindo AA, et al. Lessons learned after 10 years of IPAQ use in Brazil and Colombia. J Phys Act Health. 2010;7 Suppl 2:S259-64.

19. Troiano RP, Berrigan D, Dodd KW, Mâsse LC, Tilert T, McDowell M Physical activity in the United States measured by accelerometer. Med Sci Sports Exerc. 2008;40(1):181-8. http://dx.doi.org/10.1249/ mss.0b013e31815a51b3 
20. Trost SG, Way R, Okely AD. Predictive validity of three ActiGraph energy expenditure equations for children. Med Sci Sports Exerc. 2006;38(2):380-7. http://dx.doi.org/10.1249/01. mss.0000183848.25845.e0

21. Evenson KR, Wen F, Metzger JS, Herring AH. Physical activity and sedentary behavior patterns using accelerometry from a national sample of United States adults. Int J Behav Nutr Phys Act. 2015;12:20. http://dx.doi.org/10.1186/s12966-015-0183-7

22. Loprinzi PD, Walker JF. Nicotine Dependence, Physical Activity, and Sedentary Behavior among Adult Smokers. N Am J Med Sci. 2015;7(3):94-9. http://dx.doi.org/10.4103/1947-2714.153920

23. Freedson PS, Melanson E, Sirard J. Calibration of the Computer Science and Applications, Inc. accelerometer. Med Sci Sports Exerc. 1998;30(5):777-81. http://dx.doi.org/10.1097/00005768-19980500000021

24. American College of Sports Medicine. ACSM's guidelines for exercise testing and prescription. 8th ed. Philadelphia: Lippincott Williams \& Wilkins; 2009.

25. Masuko H, Sakamoto T, Kaneko Y, lijima H, Naito T, Noguchi E, et al. Lower FEV1 in non-COPD, nonasthmatic subjects: association with smoking, annual decline in FEV1, total IgE levels, and TSLP genotypes. Int J Chron Obstruct Pulmon Dis. 2011;6:181-9.

26. Walters MS, De BP, Salit J, Buro-Auriemma LJ, Wilson T, Rogalski AM, et al. Smoking accelerates aging of the small airway epithelium. Respir Res. 2014;15:94. http://dx.doi.org/10.1186/s12931-014-0094-1

27. Lallukka T, Rahkonen O, Lahelma E, Lahti J. Joint associations of smoking and physical activity with disability retirement: a registerlinked cohort study. BMJ Open. 2015;5(7):e006988. http://dx.doi. org/10.1136/bmjopen-2014-006988

28. Mesquita R, Gonçalves CG, Hayashi D, Costa Vde S, Teixeira Dde C, de Freitas ER, et al. Smoking status and its relationship with exercise capacity, physical activity in daily life and quality of life in physically independent, elderly individuals. Physiotherapy. 2015;101(1):55-61. http://dx.doi.org/10.1016/j.physio.2014.04.008

29. Gold DR, Wang X, Wypij D, Speizer FE, Ware JH, Dockery DW. Effects of cigarette smoking on lung function in adolescent boys and girls. N Engl J Med. 1996;335(13):931-7. http://dx.doi.org/10.1056/ NEJM199609263351304

30. Cazzola M, Calzetta $L$, Rogliani $P$, Lauro $D$, Novelli $L$, Page $C P$, et al. High glucose enhances responsiveness of human airways smooth muscle via the Rho/ROCK pathway. Am J Respir Cell Mol Biol. 2012;47(4):509-16. http://dx.doi.org/10.1165/rcmb.2011-04490C

31. Shah SH, Sonawane P, Nahar P, Vaidya S, Salvi S. Pulmonary function tests in type 2 diabetes mellitus and their association with glycemic control and duration of the disease. Lung India. 2013;30(2):108-12. http://dx.doi.org/10.4103/0970-2113.110417

32. Sandler M. Is the lung a 'target organ' in diabetes mellitus? Arch Intern Med. 1990;150(7):1385-8. http://dx.doi.org/10.1001/ archinte.1990.00390190051006

33. Kinney GL, Black-Shinn JL, Wan ES, Make B, Regan E, Lutz S, et al. Pulmonary function reduction in diabetes with and without chronic obstructive pulmonary disease. Diabetes Care. 2014;37(2):389-95. http://dx.doi.org/10.2337/dc13-1435

34. Pelkonen M, Notkola IL, Lakka T, Tukiainen HO, Kivinen P, Nissinen A. Delaying decline in pulmonary function with physical activity: a 25year follow-up. Am J Respir Crit Care Med. 2003;168(4):494-9. http:// dx.doi.org/10.1164/rccm.200208-9540C

35. Ortlieb S, Gorzelniak L, Nowak D, Strobl R, Grill E, Thorand B, et al. Associations between multiple accelerometry-assessed physical activity parameters and selected health outcomes in elderly people-results from the KORA-age study. PLoS One. 2014;9(11):e111206. http://dx.doi.org/10.1371/journal.pone.0111206

36. Caspersen CJ. Physical activity epidemiology: concepts, methods, and applications to exercise science. Exerc Sport Sci Rev. 1989;17:42373. http://dx.doi.org/10.1249/00003677-198900170-00015 